\title{
9.2 Mesoscale Eddy Formation and Shock Features Associated with a Coastally Trapped Disturbance
}

\author{
Stephen D. Burk and William T. Thompson \\ Naval Research Laboratory \\ Monterey, California
}

\section{Introduction}

On 28 August 2002, an interesting sequence of events took place in association with a coastally trapped disturbance (CTD) as it propagated along the coast of northern California. The CTD (as evidenced by a sharply defined, narrow tongue of marine stratus cloud) propagated northward against the prevailing northwesterly flow, arrived in Monterey Bay at 11:30 UTC, San Francisco Bay at 14:30 UTC, and reached Pt. Reyes at 16:30 UTC 28 August 2002. As the CTD rounded Pt. Arena at about 18:30 UTC, a dramatic, welldefined hydraulic-jump-like feature (hereafter termed a 'shock') developed north of the CTD and angled away from the coast to the southwest. Because the summertime marine boundary layer (MBL) in this coastal region often is close to saturation, an abrupt increase in MBL depth associated with a shock feature sometimes can generate recognizable, and in some cases very eyecatching, features within the cloud field (e.g., Burk and Haack 2001). Over the next 3-4 $\mathrm{h}$, the CTD continued to propagate to the north and then rolled into a striking mesoscale eddy leeward of Cape Mendocino ( $\mathrm{CM}$ ) and another eddy formed off of Pt. Arena.

Although a considerable body of literature recently has been devoted to the propagation phase of CTD events, very little study has been directed towards the CTD decay phase wherein mesoscale eddy formation is not unusual. Dorman (1985) noted that mesoscale eddies can be generated in association with CTD's and presented satellite imagery from May 1982 of a CTD along coastal California bearing similarity to the August 2002 case we analyze here. There are instances, however, when CTD's propagate the full length of the U. S. west coast, opposite to prevailing northerly flow, without developing mesoscale eddies.

Rogerson (1999) used a shallow water model to investigate the interaction of an artificially created CTD with transcritical flow in the vicinity of coastal topographic bends. Shock features develop at the southern end of an expansion fan in her study and, as the CTD propagates north along the coast, a strong lateral shear layer develops. Once CTD propagation is halted, the shear layer destabilizes and rapidly rolls up to form a vortex. Many of these same features occur in our mesoscale forecast presented here. However, the origin of the supercritical flow leeward of CM in our study is not solely due to flow acceleration in an expansion fan around CM. Supercritical flow is also produced by downslope acceleration in the lee of CM. Nonhydrostatic mesoscale model simulations of this period using the Coupled Ocean-Atmosphere Mesoscale Prediction System (COAMPS 4 model reproduce features of the event seen in satellite images and surface observations.

\section{Modeling Aspects}

The COAMPS mesoscale model used in the present study is described in Hodur et al. (2002). The model is nonhydrostatic and uses multiple nests having different horizontal resolution. It features a full suite of physical parameterizations, including a level 2.5 turbulence parameterization, radiation, and cloud microphysics schemes. Surface fluxes and surface stress are computed from the Louis scheme. Data assimilation is accomplished using a multivariate optimal interpolation (MVOI) approach.

\footnotetext{
${ }^{1}$ COAMPS is a trademark of the Naval Research Laboratory.
} 


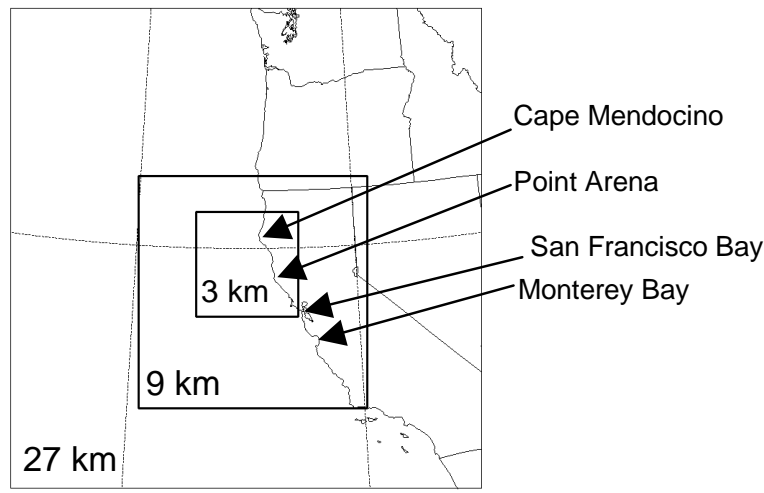

Fig. 1 COAMPS nested grid structure in this study.

The COAMPS model simulation of this event utilizes the grid structure shown in Fig 1. As indicated, the horizontal resolution of the nests is $27 \mathrm{~km}, 9 \mathrm{~km}$, and $3 \mathrm{~km}$. Three $12 \mathrm{~h}$ data assimilation forecasts were performed prior to the $12 \mathrm{~h}$ forecast beginning at 1200 UTC 28 August containing the period of interest.

\section{Case Description}

\subsection{Synoptic Discussion}

On 27 August 2002, a weak 500$\mathrm{hPa}$ trough was located over the western $U$. S. with the axis extending from Montana to Central California. At sea level, a ridge over Oregon and Washington resulted in NE offshore flow over Northern California while an inverted thermal trough was located over the southern San Joaquin Valley and the southern deserts of California. On 28 August, the trough at $500 \mathrm{hPa}$ deepened significantly; the axis extended from Montana to $\sim 100 \mathrm{~km}$ west of San Diego. The inverted thermal trough over California deepened as well and extended from just east of CM to South-Central Arizona. The ridge over the Pacific Northwest resulted in continued offshore flow over Northern California (the high in San Francisco was 29.4C; $11 \mathrm{C}$ above the monthly mean for August 2002). On 29 August, the $500-\mathrm{hPa}$ trough weakened substantially, as did the thermal trough at the surface over California.

\subsection{Satellite Imagery}

The mesoscale evolution of the event can be followed by a series of GOES10 satellite images from the afternoon of 28 August. Hereinafter, time will be specified in local time (LT=PDT=UTC-7). The image from 1300 LT 28 August 2002
(Fig. 2a) shows a cloud-free zone along the coast of Southern Oregon and Northern California. There is a large area of low clouds $50-75 \mathrm{~km}$ offshore extending along the coast over the domain of the image. The narrow cloud "tongue" that has rounded Pt. Arena is associated with the CTD.

West of the CTD at the edge of the cloud band is a series of wave clouds. These wave clouds are indicative of trapped gravity waves associated with a shock feature and are similar in appearance to wave clouds discussed by Burk and Haack (2001). The wave clouds become more distinct and have an albedo significantly larger than the surrounding low clouds.

At $1500 \mathrm{LT}$ (Fig 2b), a rather striking image shows that a pair of cyclonic eddies have formed due to the interaction of the prevailing NW coast-parallel flow and the southerly flow associated with the CTD. The northern eddy is just in the lee of CM and is delineated by fine cloud filaments wrapping around the center while the southern eddy lies just to the SW of Pt. Arena. The southern eddy is less distinct than the northern eddy in individual satellite images, but can clearly be seen in the cloud motion visualized in a satellite loop. These eddies are both $\sim 50-75 \mathrm{~km}$ in diameter. The linear features associated with the shock feature are somewhat less visible at 1500 LT, having been entangled in the northern eddy.

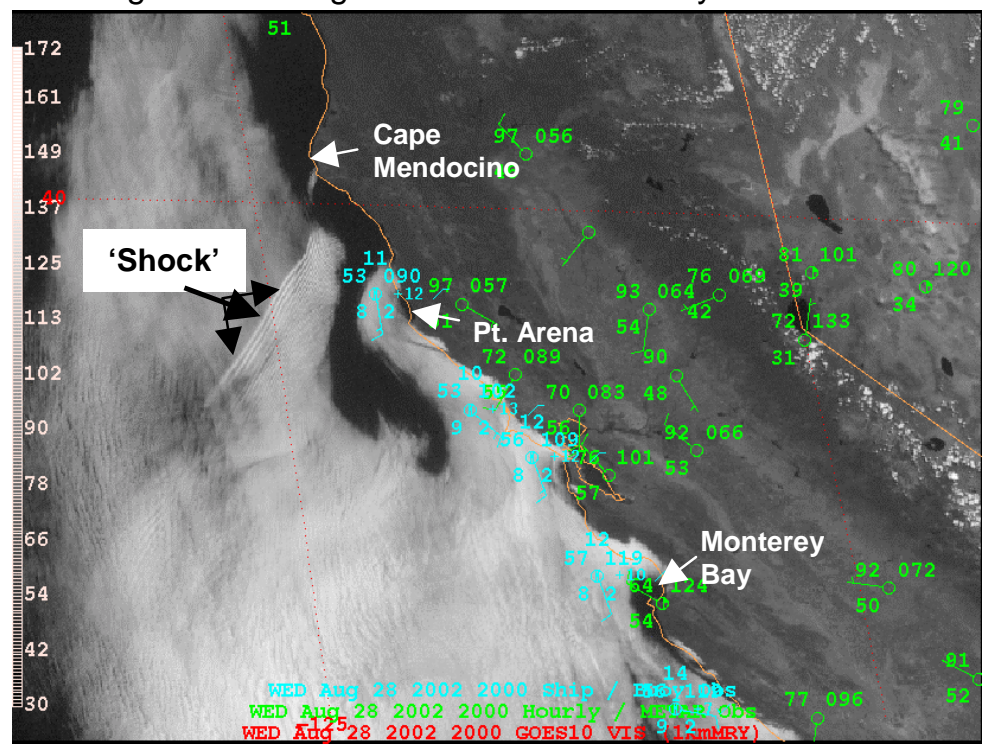

Fig. 2 GOES10 images at (a) 2000 UTC [1300 LT] and, (b) 2200 UTC [1500 LT] 28 Aug 2002. 


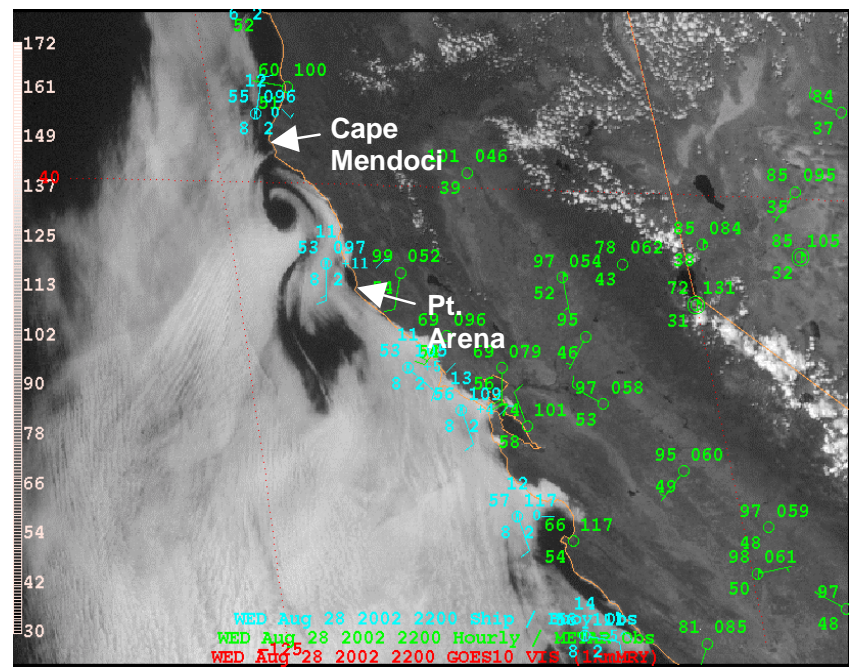

Fig. 2 (b)

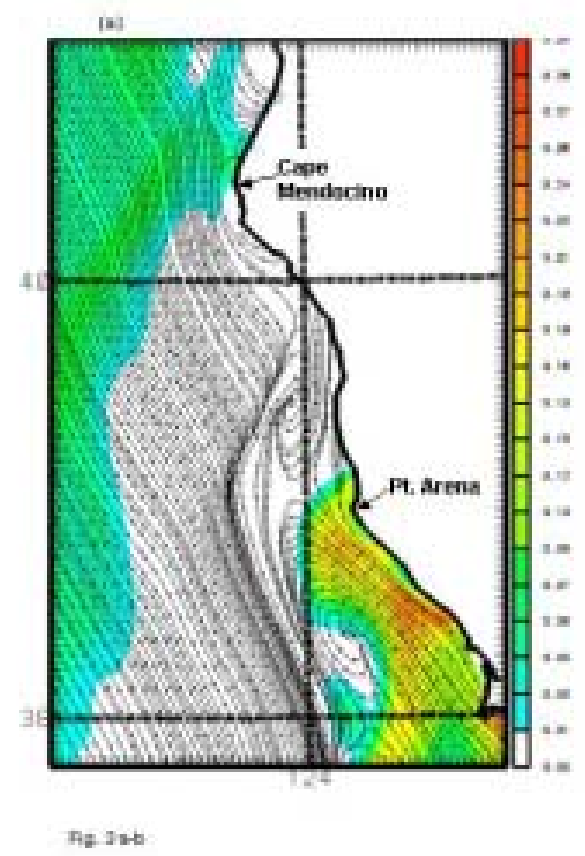

Fig. 3(a) 10-m streamlines and integrated liquid water from $12 \mathrm{~h}$ COAMPS forecast valid 1700 LT 28 Aug 2002 and, (b) 10-m vectors and shaded wind speed $\left(\mathrm{m} \mathrm{s}^{-1}\right)$ at same time.

The switch to southerly flow at a given location along the coast precedes the arrival of the cloud tongue by several hours, as evidenced by comparing buoy and satellite observations. This same lag between wind shift and cloud arrival is discussed by Ralph et al. (1998) and modeled by Thompson et al. (1997) in conjunction with a June 1994 CTD. The air in this forerunning, wind-shift region is not purely associated with southerly flow and, hence, saturation is not immediately attained upon the switch to southerly flow.

\subsection{Model Forecasts}

Shown in Fig 3a are forecasts of 10 $\mathrm{m}$ elevation streamlines and integrated cloud liquid water $\left(\mathrm{kg} \mathrm{m}^{-2}\right.$; shaded) over a zoomed area of the inner nest. Figure 3a shows the model $12 \mathrm{~h}$ forecast valid 1700 LT 28 Aug. At this time the modeled zone of sharp wind shift associated with the shock has strengthened substantially and propagated to the north in agreement with the satellite images. Both of the model eddies are well defined and southerly flow extends to just south of CM in a narrow zone along the immediate coast as suggested by the satellite images. The cloud tongue associated with the CTD has rounded Pt Arena and, as in the satellite imagery, a clear "slot" is visible over the center of the southern eddy. The cloudy area to the west has advanced toward the coast. Note that the modeled integrated cloud water is much larger within the southerly flow associated with the CTD than in the cloud shield to the west, which is consistent with the higher albedo of these clouds in the satellite images. Figure $3 b$ shows model forecast wind vectors and isotachs ( $\mathrm{m} \mathrm{s}^{-1}$; gray shaded) at $10 \mathrm{~m}$ at the same time as Fig 3a. There is strong flow acceleration in the lee of $\mathrm{CM}$, with abrupt deceleration along a line (shock) angling away from the coast to the SW. Another shock feature has formed in the blocked flow north of Cape Mendocino

\subsection{Comparison with observations}

Time series of wind speed and direction and temperature have been constructed at locations corresponding to the positions of several data buoys along the coast. The buoys are located at Pt. Piedras Blancas, Monterey Bay, San Francisco Bay, Bodega Bay, Pt. Arena, and Eel River. Comparison of the wind direction observations with model results allows tracking of the observed and modeled 


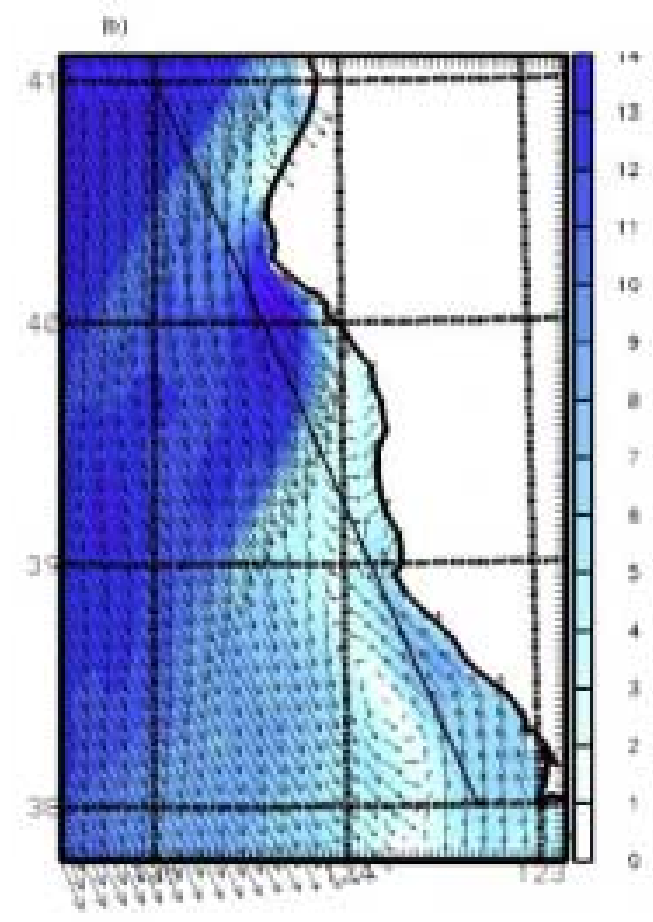

Fig 3 (b)

progress of the CTD up the coast. The comparison shows good agreement between the model and observations from Pt. Piedras Blancas, where the model and observations show a distinct shift to southerly flow at $0200 \mathrm{LT}$, to Bodega Bay, where the shift to southerly flow commences at $0700 \mathrm{LT}$ in the observations and the model results. In the observations, propagation of the CTD slows north of Bodega Bay and slows far too much at the surface in the model results. A phase lag in surface wind shift between the model and observations of $\sim 4 \mathrm{~h}$ develops at Pt. Arena. However, the model does have tongue of southerly flow just above the surface layer that extends well ahead of the surface southerly flow. In particularly, at $140 \mathrm{~m}$ the southerly flow reaches Pt. Arena at 1100 LT, only one hour later than in the surface observations. Hence, it appears that the model may be too slow in mixing this southerly flow to the surface.

\section{Shock Feature Interaction with the CTD and Eddy Roll-up}

Compression jumps, which tend to form when coastal points or capes act to block and deflect approaching supercritical flow, often take on the linear or the gently curved appearance of a bow wave. Modeling the formation of atmospheric shocks when supercritical flow impacts a convex bend in the coastline has generally been quite idealized, often making use of the shallow water equations.

In a single layered fluid, supercritical flow occurs when the Froude number ( $F r)$, a dimensionless quantity given by the ratio of the flow speed to the gravity wave phase speed, is greater than unity. Samelson (1999) investigated the properties of free and forced trapped waves in an atmosphere that includes a stable layer above the capping inversion and found the gravestmode phase speed to be increased, and higher vertical modes supported, by the presence of the extended stable layer. In fact, for an atmospheric structure as displayed in Samelson (1999; his Fig. 1a), $c=\left[\left(\gamma_{1}+\gamma_{2}\right) h\right]^{1 / 2}$ is found to be a relatively good approximation to the phase speed of the first trapped mode. Here $\gamma_{1}=g \Delta \Theta /<\Theta>$, $\gamma_{2}=g(\delta \Theta / \Theta)$ with $\Delta \Theta$ being the sharp discontinuity at the MBL top, and $\delta \Theta$ being the potential temperature change across the extended stable layer above the capping inversion, and $\mathrm{h}$ the MBL depth. The phase speed and layer depth we use in our COAMPS Froude number computations is similar to that described above.

Because of this imprecision in specifying a meaningful $\mathrm{Fr}$ value (for stratified flow) as an indicator of regimes of flow transition, we examine regions of sharp horizontal gradients in $\mathrm{Fr}$ within which the $\mathrm{Fr}=1$ line is embedded, rather than simply focusing on the $\mathrm{Fr}=1$ line itself. This is illustrated in Fig. 4, which displays a $12 \mathrm{~h}$ forecast of model computed Fr valid at 1700 LT 28 Aug 2002. Maximum $\mathrm{Fr}$ values greater than 1.6 occur leeward (south) of $\mathrm{CM}$. This high $\mathrm{Fr}$ region is created by two processes; namely, flow acceleration down the lee slope of CM associated with a mountain gravity wave and low-level cornering flow (expansion fan). Also, a local maximum in Fr occurs adjacent to the coast south of Point Arena that is not due to an 
(a)

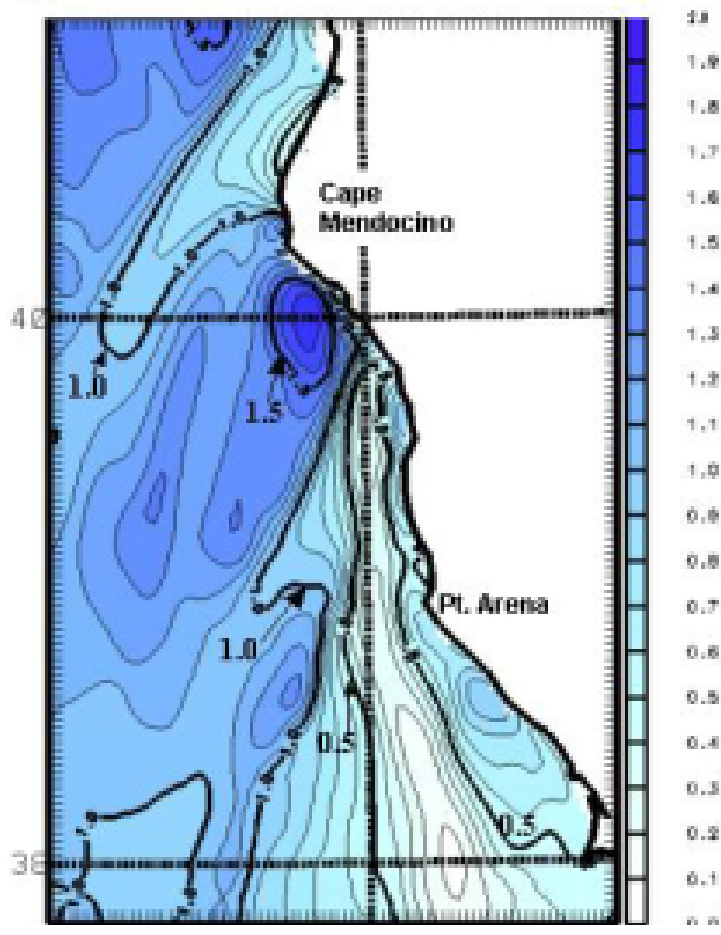

Fig. 4 COAMPS forecast Froude number at same time as Fig. 3

expansion fan but rather the strong, southerly flow associated with the propagating CTD that has entered this region.

Most noteworthy in Fig. 4 is the region of strong horizontal Fr-gradient, which encompasses the $\mathrm{Fr}=1$ contour that angles away from the coast at the southern end of the CM expansion fan. There also is a pronounced Fr gradient north of CM that is indicative of a shock feature and, indeed, there is evidence of this feature in the satellite cloud imagery as well, albeit somewhat more subtle.

Figure 5 depicts the COAMPS forecast of the $0.05 \mathrm{~g} \mathrm{~kg}^{-1}$ isosurface of cloud liquid water, along with $10-\mathrm{m}$ wind speed $\left(\mathrm{m} \mathrm{s}^{-1}\right)$ and streamlines at $1700 \mathrm{LT}$. The linear cloud lines evident in the satellite imagery (Fig. 2a) are oriented at $\sim 125^{\circ}$ from north, which is approximately the angle at which the modeled linear shock feature (Fig. 5 ) forms. Also, the tight gradient associated with the modeled shock extends over a length of $\sim 100 \mathrm{~km}$, which is approximately that of the observed cloud lines.

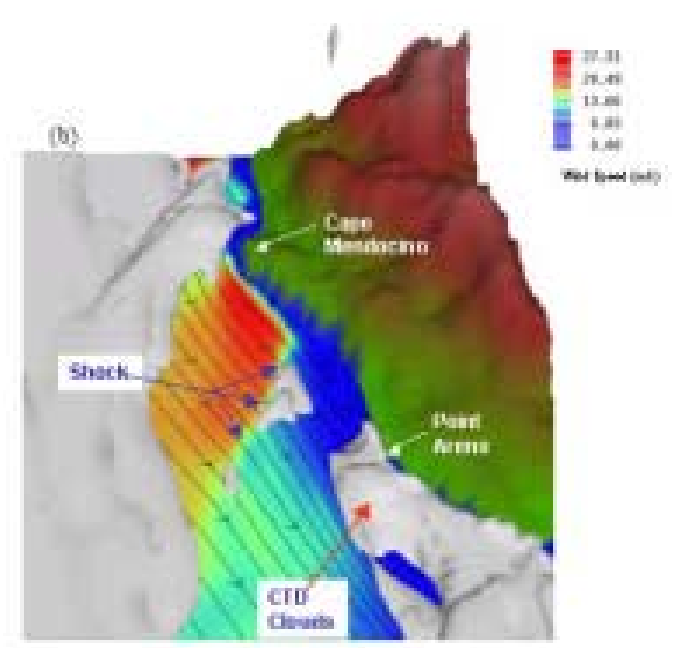

Fig. 5 COAMPS $12 \mathrm{~h}$ forecast $10-\mathrm{m}$ streamlines, wind speed shaded $(\mathrm{m}$ $\left.\mathrm{s}^{-1}\right)$, and cloud water isosurface $(0.05$ $\mathrm{g} \mathrm{kg}^{-1}$ ) at same time as Fig. 3

Although Fig. 5 shows that the model's wind field has captured the shock feature, the cloud features along the shock are poorly represented. Higher resolution than the $3 \mathrm{~km}$ inner nest is required to adequately describe the undular wave clouds associated with the shock. In agreement with the satellite image (Fig. 2a), however, the modeled cloud field (Fig. 5) does show a clear gap between the cloud line along the shock and the coastline. This gap in the clouds arises because the MBL shallows progressively as the expansion fan/ downslope flow approaches the coast and consequently the inversion capping the MBL drops below the lifting condensation level.

The modeled southerly flow in the MBL associated with the CTD is strong (10$\mathrm{m}$ wind speed maximum $\sim 8 \mathrm{~m} \mathrm{~s}^{-1}$ ) as it rounds Point Arena, however the CTD fails to round $\mathrm{CM}$ and instead, in agreement with the observations, wraps into two eddies. Rogerson (1999) explored the dynamic characteristics of hydraulically transcritical flows adjacent to a spatially varying coastline; that is, flows having localized supercritical $(\mathrm{Fr}>1)$ regions embedded within a domain that generally is subcritical $(\mathrm{Fr}<$ 1). While CTD's are able to propagate northward in the subcritical region of the base flow, they can be severely attenuated, or halted altogether, upon encountering a 
supercritical region. In our real data forecast, prior to the CTD's approach to Point Arena the model computed Fr field has only a very small supercritical area in the lee of this Point, but a much stronger fan (with $\mathrm{Fr}>2.0$ ) leeward of $\mathrm{CM}$, with a sizeable region encompassed by the $\mathrm{Fr}=1.5$ contour. Consistent with Rogerson's study, the CTD modeled here is able to propagate northward beyond Point Arena, but is halted at $\mathrm{CM}$. The area encompassed by the $\mathrm{Fr}=$ 1.5 contour has shrunk considerably by 1700 LT 28 Aug. (Fig. 4), and is absent by 2100 LT on the $28^{\text {th }}$ (not shown), although the flow in a small region in the immediate lee of the Cape remains supercritical.

The COAMPS divergence and absolute vorticity fields in the MBL $(140 \mathrm{~m})$ are shown in Fig. 6a-b at 1700 LT 28 August 2002. Strong convergence zones are evident (Fig. 6a) associated with the modeled shock features either side of $\mathrm{CM}$, while there is divergence in the accelerating flow leeward of the Cape. Prior to 1300 LT (not shown) the convergence zone angling away from the coast is weak and unorganized.

Vorticity is clearly enhanced in association with the shock feature (Fig. 6b). Epifanio and Durran (2002) modeled idealized flow over a uniform ridge and investigated the mechanisms of vorticity production associated with a hydraulic-jump feature that develops leeward of the ridge. They find that the vertical stretching term [i.e., $(\varsigma+f) \nabla . V]$ in the jump significantly amplifies the upstream relative vorticity. Based on the divergence field shown in Fig. $6 \mathrm{a}$, which indicates strong convergence along the shock line, vorticity stretching also appears likely to be a significant factor in generating the vorticity enhancement seen along the shock in this study. Of course, potential vorticity (PV) is a conservative quantity; stretching and tilting of relative or absolute vorticity does not generate PV. However, there is generation of PV along the shock feature in this study associated with dissipative processes within the jump. This PV enhancement can best be seen in a vertical cross section across the jump.

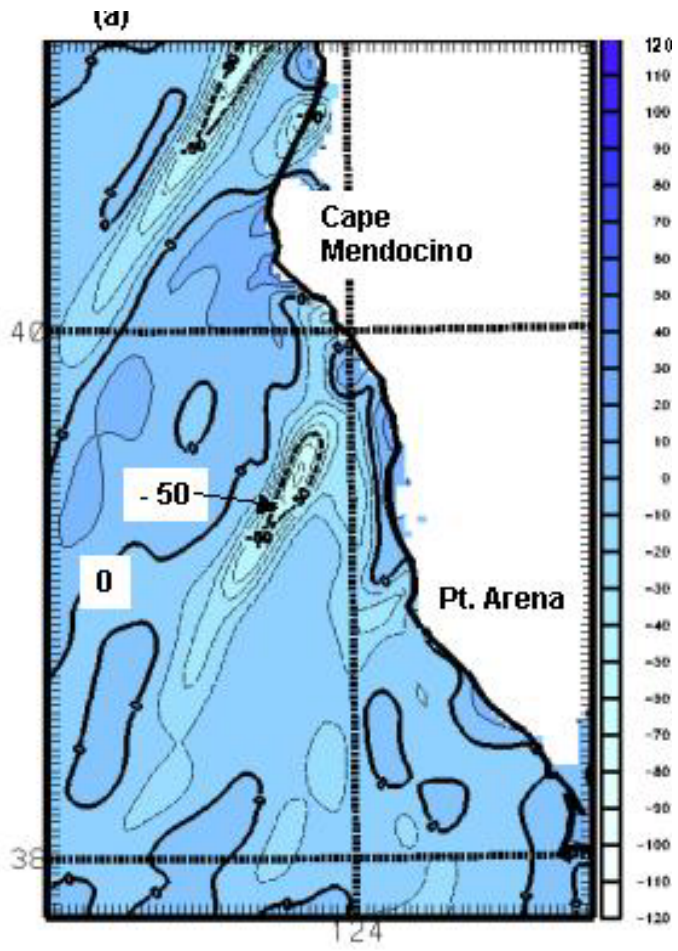

Fig. 6 (a) COAMPS $12 \mathrm{~h}$ forecast of divergence $\left(10^{-5} \mathrm{~s}^{-1}\right)$ at $140 \mathrm{~m}$ valid 1700 LT 28 Aug 2002 and, (b) absolute vorticity $\left(10^{-5} \mathrm{~s}^{-1}\right)$ at same height and time as (a).

Figure $7 \mathrm{a}$ shows the potential temperature $(\mathrm{K})$ in the plane of cross section E-F (Fig. $6 \mathrm{~b})$, and Fig. $7 \mathrm{~b}$ displays the PV in this same plane. Both Fig. 7 a-b are from a $12 \mathrm{~h}$ COAMPS forecast valid 1700 LT 28 August 2002.

\section{Discussion and Conclusions}

In the present study, we investigate an event in which a CTD propagating northward along the coast past Point Arena encounters supercritical flow in the lee of Cape Mendocino. Satellite imagery shows that a compression shock forms south of Cape Mendocino, angling away from the coast. The shock feature propagates to the 


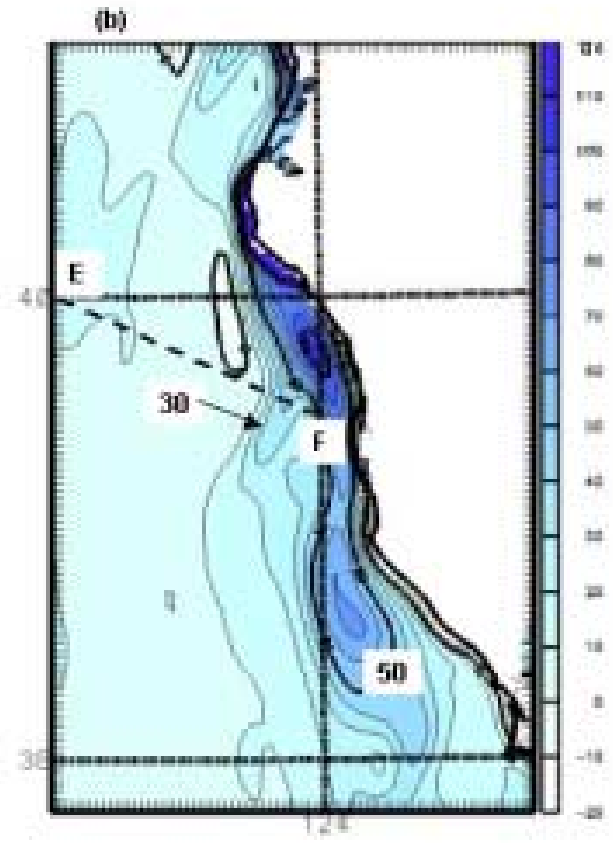

Fig. 6 (b)

north for several hours and then becomes rolled up into a cyclonic eddy. The Naval Research Laboratory's nonhydrostatic COAMPS model is used to simulate this period. The model results compare quite favorably with satellite imagery and coastal buoy observations, provided allowance is made for the modeled CTD phase speed being too slow near Pt. Arena.

Numerous recent investigations (including field studies) have been conducted addressing the propagation phase of CTD's, but there has been relatively little study of the initiation or dissipation phases of CTD's. The coastal processes present in this case study are not particularly rare; indeed transcritical conditions are found in the lee of points and capes in the mean summer (June-July) model average (Dorman et al. 2000) and CTD's occur several times each year, often spawning cyclonic eddies in conjunction with cessation of propagation. The event described herein, however, features all of these processes and incorporates the highly nonlinear interaction among them, including the northward propagation of the shock

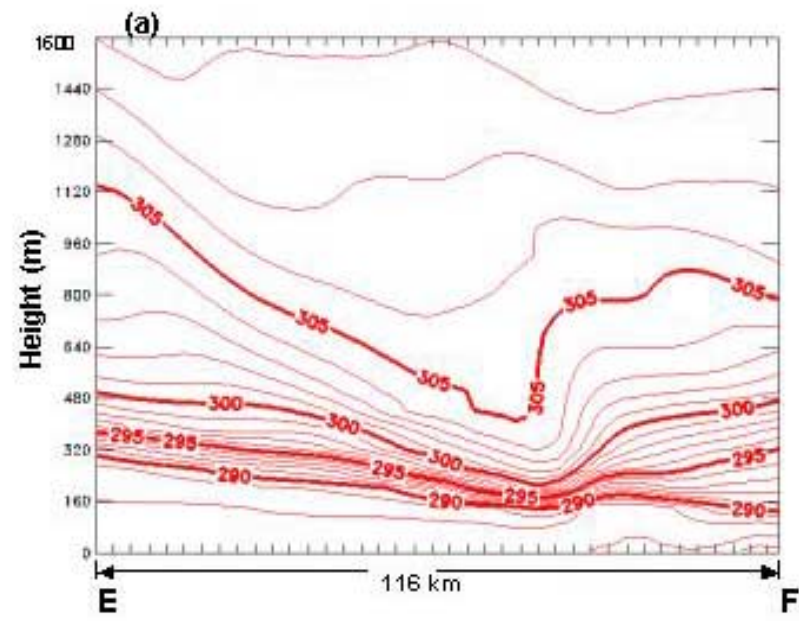

Fig. 7 (a) COAMPS $12 \mathrm{~h}$ forecast of potential temperature $(K)$ in section E-F of fig. $6 b$ valid 1700 LT 28 Aug 2002 and, (b) potential vorticity (PVU) in the same plane at the same time as (a).

(b)

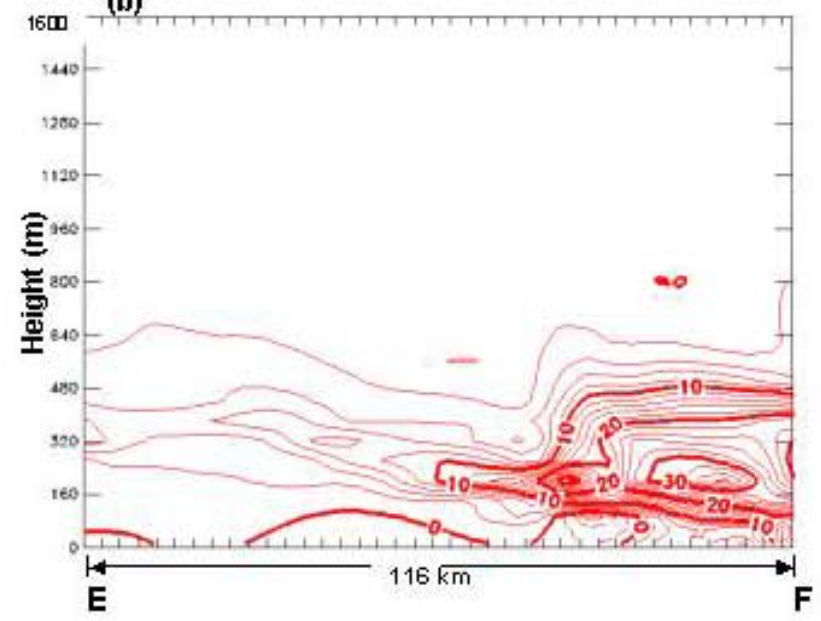

Fig. 7 (b) 
feature, the sharp variations in boundary layer depth associated with both the shock feature and the leading edge of the CTD, and the strong horizontal shear associated with the NW flow offshore and the southerly flow in the CTD aiding development of the cyclonic eddies.

Both the observed and modeled CTD round $\mathrm{Pt}$. Arena with apparent ease and show rather strong southerly flow north of this Point. However, both the observed and modeled CTD stall and roll-up into a mesoscale eddy upon approaching CM. Prior to this eddy roll up, vorticity and PV are both clearly enhanced across the shock feature. The strong low-level convergence along the leading edge of the shock and the jump in boundary layer depth are favorable for vorticity enhancement by stretching (Epifanio and Durran 2002). But, alone this process only produces a modest increase in vorticity along the length of the shock (Fig. $6 b)$. However, as the CTD approaches the shock feature, the combined interaction of these jump features acts to strongly enhance the vorticity at the leading edge of the CTD (note strong maximum south of CM along the coast in Fig. 6b). And, this is the point when the leading edge of the CTD first begins to roll up into a mesoscale vortex.

The eddy that forms off of Pt. Arena does not appear to form in the same manner as just described for the northern eddy. The southern eddy forms along the strong shear line between the southerly flow rounding $\mathrm{Pt}$. Arena and the background northerly flow. This eddy appears to grow by shear (barotropic) instability wherein the perturbation directly extracts energy from the mean shear. This is further indicated by the orientation of this eddy relative to the shear vector (see Pedlosky, 1979).

\section{ACKNOWLEDGEMENTS}

We gratefully acknowledge Prof. R. T. Williams for helpful discussions and Dr. Peter Guest for bringing this CTD event to our attention. This research was supported by the Office of Naval Research Program Element $0601153 \mathrm{~N}$.

\section{References}

Burk, S.D. and T. Haack, 2001: The dynamics of wave clouds upwind of coastal orography. MWR., 128, 1438-1455.

Dorman, C.E., 1985 : Evidence of Kelvin waves in Cailfornia's marine layer and related energy generation. $M W R, \mathbf{1 1 3}$, 827-839.

-----, T. Holt, D.P. Rogers, and K. Edwards, 2000: Large-scale structure of the JuneJuly 1996 marine boundary layer along California and Oregon. MWR, 128, 1632 1652.

Epifanio, C.C., and D.R. Durran, 2002: Leevortex formation in free-slip stratified flow over ridges. II: Mechanisms of vorticity and PV production in nonlinear viscous wakes. J. Atmos. Sci., 59, 1166-1181.

Hodur, R. M., J. Pullen, J. Cummings, X. Hong, J.D. Doyle, P. Martin, and M.A. Rennick, 2002: The coupled ocean/atmospheric mesoscale prediction system (COAMPS). Oceanography, 15, 88-89.

Pedlosky, J., 1979: Geophysical Fluid Dynamics. Springer-Verlag, 624 pp.

Ralph, F. M., L Armi, J. M. Bane, C. Dorman, W. D. Neff, P. J. Neiman, W. Nuss, and P.O.G. Persson, 1998 : Observations and analysis of the 10-11 June coastally trapped disturbance. MWR, 126, 2435-2465.

Rogerson, A. M., 1999: Transcritical flows in the coastal marine atmospheric boundary layer. J. Atmos. Sci., 56, 2761-2779.

Samelson, R. M., 1999: The vertical structure of linear coastal-trapped disturbances. MWR, 127, 201-213. Thompson, W. T., T. Haack, J. D. Doyle, and S. D. Burk, 1997: A nonhydrostatic mesoscale simulation of the 10-11 June 1994 coastally trapped wind reversal. MWR, 125, 3211-3230.

Corresponding author: Stephen D. Burk, Naval Research Laboratory, Marine Meteorology Division, 7 Grace Hopper Ave., Monterey, CA 93943-5502 :

burk@nrlmry.navy.mil 